\title{
The centenary of Hereditas - almost a fairytale
}

\author{
Yongyong Shi ${ }^{1}$ and Stefan Baumgartner ${ }^{2^{*}}$
}

\begin{abstract}
This is the Editorial for a series of articles illuminating the history and success story of Hereditas, one of the oldest journals in the area of genetics. For this reason, we invite you to read this special series on a journal with a distinct reputation and which can celebrate its Centenary in 2020.
\end{abstract}

\section{Background}

The fairytale of Hereditas began in 1920 when a group of geneticists, the previous founders of the Mendelian Society in Lund in 1910 decided that they needed a platform to be able to publish scientific articles and to reach out to colleagues and scientists outside of Sweden. This led to the establishment of Hereditas in 1920. The sequence of events is meticulously narrated by [1]. Two protagonists promoting the foundation of Hereditas should be named here: Herman Nilsson-Ehle (18731949) and Robert Larsson (1885-1956). The latter also became the first Editor-in-Chief (EiC) holding this post for more than 3 decades from 1920 to 1954, followed by Arne Müntzing (1955-1977), Arne Lundqvist (19781988), Karl Fredga and Arne Lundqvist (1989-1996), Ulf Gyllensten (1996-2001), Anssi Saura (2002-2011), Stefan Baumgartner (2012 -), and Yongyong Shi (2016 -, in parallel to Baumgartner).

In 2005, an important decision was taken by the $\mathrm{EiC}$ at the time, Anssi Saura, to change the subscription format of Hereditas to open-access (OA), thus helping to pioneer the path of OA-journals. This led to an increase of submissions and provided immediate access to Hereditas to all scientists world-wide. Another wise decision was taken in 2011 when the owner of Hereditas, the Mendelian Society of Lund, sponsored by the Erik

\footnotetext{
* Correspondence: Stefan.Baumgartner@med.lu.se

2Department of Experimental Medical Sciences, Lund University, 22100 Lund, Sweden

Full list of author information is available at the end of the article
}

Philip-Sörensen Foundation, decided to digitalize all back-issues from the very first one in 1920 (Fig. 1). It was an extraordinarily important decision to ensure that all back-issues were available to the scientific readership. In 2013 and 2014, the journal experienced a dramatic drop of submissions which forced the EiC to terminate its activity at the end of 2014. In an astonishing turn of events, a few months later, the journal experienced a resurrection with the collaboration with a new publisher, Springer Nature which in retrospect became an extremely beneficial union for both sides.

We have divided this Centenary issue into topical areas. These sections represent prominently covered topics by Hereditas over the last 100 years: cytogenetics, race biology, crop genetics and evolution. The topical series will be complemented by a bibliometric overview on all articles published by Hereditas. Some of the articles proved to be "high flyers" with a high number of citations. Of note is a report in the area of cytogenetics on a proposal for a common nomenclature for centromeric positions on chromosomes, published in 1964 [2]. This publication was cited about 8000 times (source: Google Science). No lesser attention should to be given to an article that presented for the first time the number of chromosomes in humans [3]. From today's perspective, it is inconceivable that it took such an extraordinary amount of time for the scientific community to accept that humans have 46 chromosomes. The laboratory in Lund where this seminal publication originated from is commemorated by a metal plate. The story and credits

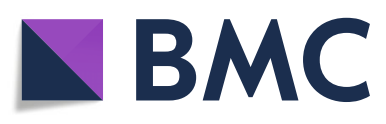

(C) The Author(s). 2020 Open Access This article is licensed under a Creative Commons Attribution 4.0 International License, which permits use, sharing, adaptation, distribution and reproduction in any medium or format, as long as you give appropriate credit to the original author(s) and the source, provide a link to the Creative Commons licence, and indicate if changes were made. The images or other third party material in this article are included in the article's Creative Commons licence, unless indicated otherwise in a credit line to the material. If material is not included in the article's Creative Commons licence and your intended use is not permitted by statutory regulation or exceeds the permitted use, you will need to obtain permission directly from the copyright holder. To view a copy of this licence, visit http://creativecommons.org/licenses/by/4.0/ The Creative Commons Public Domain Dedication waiver (http://creativecommons.org/publicdomain/zero/1.0/) applies to the data made available in this article, unless otherwise stated in a credit line to the data. 




Fig. 1 The "holy grail" of Hereditas: volume 1 from 1920 along with the whole collection of back issues. The collection is located in Lund (Sweden). Note the sign of the Mendelian Society of Lund on the top of the book spine

for this discovery is also illuminated in by an article of this topical series.

The Centenary year 2020 also experienced a dramatic increase of the impact factor (IF) to a whopping 2.4. This figure is a clear sign that scientists regard Hereditas as a valid platform to publish their data. Consequently, a record number of submissions were received, exceeding the number in 2019 by a factor of 2 . While this increased number of submissions was encouraging, the EiCs decided this year to raise the quality threshold for incoming manuscripts to avoid another increase of manuscripts.

\section{Conclusions}

The current EiCs wish to thank all past scientific members of Hereditas, be it the previous EiCs, subject Editors or Technical Editors for their significant contributions towards the success of this journal. We also wish to thank former and present publishers, Wiley and Springer Nature for their benevolence. Without all the abovementioned actors, the story of Hereditas would probably have been narrated to future generations as a fairytale, simply because how many scientific journals can boast the celebration of a Centenary?

\section{Acknowledgements \\ S. B. thanks the Swedish Research Council, the Ekhaga, Thurings and Erik Philip-Sörensen Stiftelser for support, and Linda Wei for comments on the manuscript.}

\section{Authors' contributions}

S. B. was responsible for Fig. 1, and Y. S. and S. B. for writing of the manuscript. The author(s) read and approved the final manuscript.

\section{Funding}

Swedish Research Council, award number 2010-4358

Ekhaga Foundation

Erik Philip-Sörensen Foundation

Nilsson Ehle Foundation

Thurings Foundation

\section{Availability of data and materials}

The datasets generated during and/or analyzed during the current study are available from the corresponding author on reasonable request.

\section{Ethics approval and consent to participate}

Not applicable.

\section{Consent for publication}

Not applicable.

\section{Competing interests}

The author declares that he has no competing interests.

\section{Author details}

${ }^{1}$ Bio-X Institutes, Shanghai Jiao Tong University, Shanghai 20030, China. 2Department of Experimental Medical Sciences, Lund University, 22100 Lund, Sweden.

Published online: 07 November 2020

\section{References}

1. Hoglund M, Bengtsson BO. The origin of the Mendelian Society in Lund and the start of Hereditas. Hereditas. 2014;151(6):110-4.

2. Levan A, Fredga K, Sandberg A. Nomenclature for centromeric position on chromosomes. Hereditas. 1964;52(2):201-20.

3. Tjio J, Levan A. The chromosome number of men. Hereditas. 1956;42(1-2): $1-6$.

\section{Publisher's Note}

Springer Nature remains neutral with regard to jurisdictional claims in published maps and institutional affiliations. 